\title{
Combined Municipal Solid Waste and Biomass System Optimization for District Energy Applications
}

\author{
Athanasios A. Rentizelas ${ }^{1}$, Athanasios I. Tolis ${ }^{2}$, Ilias P. Tatsiopoulos ${ }^{3}$ \\ Sector of Industrial Management and Operational Research, School of Mechanical Engineering, \\ National Technical University of Athens, \\ 9 Iroon Polytechniou str., GR-15780 Zografos, Athens, Greece
}

\begin{abstract}
Municipal Solid Waste (MSW) disposal has been a controversial issue in many countries over the past years, due to disagreement among the various stakeholders on the waste management policies and technologies to be adopted. One of the ways of treating/disposing MSW is energy recovery, as waste is considered to contain a considerable amount of bio-waste and therefore can lead to renewable energy production. The overall efficiency can be very high in the cases of co-generation or tri-generation. In this paper a model is presented, aiming to support decision makers in issues relating to Municipal Solid Waste energy recovery. The idea of using more fuel sources, including MSW and agricultural residue biomass that may exist in a rural area, is explored. The model aims at optimizing the system specifications, such as the capacity of the base-load Waste-to-Energy facility, the capacity of the peak-load biomass boiler and the location of the facility. Furthermore, it defines the quantity of each potential fuel source that should be used annually, in order to maximize the financial yield of the investment. The results of an energy tri-generation case study application at a rural area of Greece, using mixed MSW and biomass, indicate positive financial yield of investment. In addition, a sensitivity analysis is performed on the effect of the most important parameters of the model on the optimum solution, pinpointing the parameters of interest rate, investment cost and heating oil price, as those requiring the attention of the decision makers. Finally, the sensitivity analysis is enhanced by a stochastic analysis to determine the effect of the volatility of parameters on the robustness of the model and the solution obtained.
\end{abstract}

Keywords: Optimization, Municipal Solid Waste, Waste Management, Biomass, Energy Conversion, District Energy.

\footnotetext{
${ }^{1}$ Corresponding author: Athanasios Rentizelas; 9 Iroon Polytechniou Str., Zografou, 15780, Athens, Greece; Tel: +30-210-7722383; Fax: +30-210-7723571; E-mail: arent@central.ntua.gr

2 atol@central.ntua.gr

3 itat@central.ntua.gr
} 


\section{Introduction}

Waste management has been a topic of major concern lately. Public opposition to siting waste management facilities in several countries such as Greece, due to concerns about potential health effects and land value loss, as well as the adoption of the official EU Waste Framework Directive, have significantly changed the way waste should be managed. Furthermore, the increasingly stricter environmental restrictions have increased multifold the cost of treating waste, and especially Municipal Solid Waste (MSW). Developed countries have made significant efforts to devise alternative waste management strategies to landfilling, leading to the development of new technologies and systems. On the other hand, developing or transitional countries may currently generate lower amounts of MSW per capita, but the rate of increase is high and their current MSW management practices are not always as advanced as those used in developed countries. Therefore, these developing countries could benefit from adopting MSW management technologies used by developed countries.

One of the currently proposed ways of treating waste is the high temperature thermal treatment with energy recovery, as waste is considered to contain a considerable amount of bio-waste, which can lead to renewable energy production. Some authors state that energy recovery is required, if the goals set for the waste utilization rate are to be achieved (Luoranen and Horttanainen, 2007). The advantages of high temperature thermal treatment with energy recovery from waste are mainly the significantly reduced waste volume remaining for landfilling -usually the output is about $10 \%$ of the incoming volume (EC, 2006; World bank, 1999)-, the reduction of land used, the reduction of total greenhouse gas emissions and the potential for generating electricity or co-generation/tri-generation.

This work focuses on a rural area in Greece, where, apart from MSW, several types of agricultural residue biomass exist. Despite the fact that Greece belongs to the developed 
countries group, its waste management system is almost entirely based on landfilling with low rates of recycling and no energy recovery from waste, thus having a different structure than most West-European countries (Eurostat, 2011).

The scope of this work is to present a model for optimizing the location of a Waste-to-Energy (WtE) facility in a rural area, which uses MSW and waste biomass. The optimization is performed in financial terms, identifying the system configuration with the highest investment yield for the investor, or equally the least cost for the stakeholders, who are mainly the citizens of the region examined. The model includes several aspects of a waste management system, such as technical constraints (e.g. minimum heating value of the fuel used in the high temperature thermal treatment with energy recovery unit), logistical operations, distance from existing inhabited areas, etc. Furthermore, more than one fuel source may be used in the same facility, securing its year-round operation and fuel supply, as well as ameliorating the fuel mix characteristics.

The paper is organized as follows: In section 2, a literature survey is performed. In section 3 , a description of the mathematical formulation of the model is presented. The case study description is provided in section 4 . Section 5 presents the results of the model and the discussion on them and section 6 the sensitivity analysis. Finally, in section 7 the conclusions of the study are summarized.

\section{Literature review}

Energy conversion of MSW is included in the waste management system of many countries. For example, the United States had about 872 operational MSW-fired power generation plants in the year 2007 (EPA, 2011), generating approximately 2,500 megawatts, whereas in Europe, about $20 \%$ of the waste generated in the year 2009 was incinerated in about $440 \mathrm{WtE}$ plants 
(CEWEP, 2011). Several authors acknowledge the significant further potential for sustainable energy generation from MSW (Demirbas et al., 2009, Singh et al., 2011).

Several points of criticism were raised in the past concerning energy generation from MSW. Firstly, attention should be given to the management of the ashes produced, as they may contain toxic substances such as heavy metals. Some researchers claim that these ashes may be used for several alternative uses, such as in cement or road infrastructure, instead of being landfilled. Another point of criticism in introducing energy conversion of MSW in the early stages of waste incineration technology was the concern about the health effects from dioxin and furan emissions in the flue gases. However, the new technologies adopted and the new stricter emissions regulations in many countries have reduced these emissions to such an extent that WtE facilities are no longer considered a significant source of dioxin and furan emissions (Barbonaba et al., 2011; McKay, 2002; Morselli et al., 2011; Porteous, 2001).

Several authors compared the various technological solutions for generating energy from waste, such as Fruergaard and Astrup (2011), who used an LCA methodology for mixed high calorific waste suitable for Solid Recovered Fuels production, as well as source-separated organic waste. They concluded that mass burn incineration with efficient energy recovery is a very competitive solution overall. In the same vein, Münster and Lund (2010) compared eight different Waste-to-Energy technologies with a focus on fuel efficiency, $\mathrm{CO} 2$ reductions and costs. They concluded that biogas and thermal gasification are interesting future alternatives of waste incineration for about only one third of the waste currently incinerated, while at the same time they acknowledged that the remaining fractions should still be incinerated with priority to combined heat and power plants with high electric efficiency. Similarly, Münster and Meibom (2011) found incineration to be the most economically feasible solution for mixed waste. Apart from incineration, energy conversion may be performed by gasification, 
which is a more elaborate method for energy conversion of waste. For example, Koukouzas et al. (2008) examined the case of co-gasification of MSW and coal, but reached the conclusion that it is not profitable. In the same vein, Ramzan et al. (2011) developed a simulation model for hybrid biomass gasification and applied it specifically to the cases of food, municipal solid and poultry waste. Their work focused on the technological aspects of gasification and did not comment on its cost-effectiveness. Therefore, incineration appears to be currently the most cost-effective technological solution for generating energy from waste. For this reason, the incineration technology has been adopted in this work.

Some authors have researched the issue of locating WtE facilities. Perkoulidis et al. (2010) presented a mixed-integer linear programming (MILP) model for the determination of optimum locations of transfer stations, for an efficient supply chain between the waste producers and the WtE facility, aiming at minimum cost supply of the facility, focusing though solely on electricity generation. The facility location problem has also been dealt with in the biomass logistics literature. Cundiff et al. (1997) presented a linear programming optimization model to optimize a cost function including the biomass logistics activities between the on-farm storage locations and the centrally located power plant, construction and expansion costs of storage facilities, as well as the cost of violating storage capacity or lost revenue in case of biomass deficit. Other authors have included the biomass-to-energy conversion facility in their models (Tatsiopoulos and Tolis, 2003; Voivontas et al., 2001). Some researchers have developed demand driven biomass-to-energy models, such as the model presented in this work. More specifically, Nilsson (1999) modelled a biomass supply chain of two fuels (straw and reed canary grass) for district heating applications, the bioenergy facility location being defined by the model user and the intermediate storage locations calculated by the simulation model. A similar, but only single-biomass, approach was adopted by Nagel (2000) to cover existing heating demand with district heating network. 
The problem was formulated as a MILP optimization problem using a dynamic evaluation of economic efficiency and binary operators to determine whether to construct or not a district heating network, a heating plant or a co-generation plant at pre-defined potential locations. Finally, a combination of GIS, mathematical modelling and optimization for energy supply from forest biomass at a regional level was presented by Freppaz et al. (2004). The system in question attempts to partially satisfy locally existing heat and electricity needs.

Few researchers have included simultaneously MSW and biomass as potential fuel sources, as in the work of Papadopoulos and Katsigiannis (2002), who have also taken into account the potential need of an extra conventional fuel source to achieve the fuel mix critical heating value. The authors focused mainly on siting the bioenergy facility to reduce the biomass logistics costs, and more specifically, on eliminating biomass warehousing needs by performing a two-stage optimization: firstly, the CHP (Combined Heat and Power) plant location is determined to minimize the transportation distance and secondly, dynamic programming optimization is employed to identify the optimum biomass fuel mix. Dornburg and Faaij (2006a) addressed this issue at the strategic level, developing an optimization model for optimising a biomass and waste treatment system that is composed of several treatment installations, which are characterised by scale, location and kind of technology. The aforementioned model is applied in the case study of the whole Dutch waste treatment system (Dornburg and Faaij, 2006b), encompassing a broad variety of technologies for material recycling, conversion of biomass and/or waste to heat and electricity or transportation fuel.

The main challenges of combined MSW and biomass use are primarily the slagging properties and corrosion of grate furnaces, as well as the relatively high emissions of flue gas. Therefore, the recent trend of analysis has focused mainly on technical issues, such as the optimal proportions of MSW and biomass that can reduce or even eliminate these effects. In the work 
of Laryea-Goldsmith et al. (2011) it has been shown that using MSW as a supplemental fuel to biomass-fired fluidised beds might reduce the emissions of some gas pollutants, provided that the MSW content in the fuel mix is regulated prior to combustion. In a MSW incineration power plant in North China (Xie and Zhang, 2013), co-firing with biomass showed that the running efficiency of the generator unit had achieved the optimum state when the blending ratio was $14 \%$ biomass in the mix (w\%); the concentration of fly ash decreased greatly, but the concentration of $\mathrm{SO}_{2}$ and $\mathrm{NO}_{\mathrm{X}}$ were increased slightly. Finally, Nowak et al. (2012) aimed to identify the optimal proportion of woody biomass and Solid Recovered Fuels (SRF). They have also shown that firing the appropriate biomass/SRF mixture helps to protect the firing system against slagging. Last but not least, they have proven that adjusting the sulphur-tochlorine factor by adding elemental sulphur to the fuel during co-firing has a corrosion reducing potential under certain conditions.

As far as emissions reduction eligibility is concerned, the Clean Development Mechanism has already been used for funding projects that improve MSW management in developing countries. According to the work of Unnikrishnan and Singh (2010), it is interesting to note there were already 119 energy recovery projects from MSW examined in the frames of the CDM mechanism, out of which 88 projects involved generation of electricity that is supplied to the grid, similarly to the case examined in this work. In the same vein, Barton et al (2008) examine the options for funding MSW management projects in developing countries through the CDM mechanism. Energy exploitation of waste has also been examined, mainly in areas with lack of space for landfills, such as in the work of Kathirvale et al. (2004) for Malaysia.

The main innovation of this work lies in the fact that it deals with combined MSW and biomass energy exploitation while simultaneously focuses on system-wide investment optimization. This concept has not been adopted in the relevant literature up to now. 


\section{Model}

\subsection{Conditions/assumptions of the model.}

The model presented here aims to simulate and optimise a Municipal Solid Waste (MSW) management system that incorporates a Waste-to-Energy ( $\mathrm{WtE})$ facility. The energy generated may be in the form of electricity and heat, which is a co-generation scenario, and also in the form of cooling, which is a tri-generation scenario. The model is designed to be demand-driven, meaning that it aims to supply the final customers with the energy products (heat and/or cooling) they require. Electricity is fed to the grid; therefore, there is no restriction into how much and when it will be generated. The model allows the use of multiple fuel sources, which means other biomass sources apart from MSW may be used. Several design and operational aspects of the system form the variables of the optimization problem, aimed at maximizing the Net Present Value (NPV) of the investment. The optimization variables refer to a yearly planning period; however, the model performs calculations concerning energy and fuel-related parameters at a monthly period.

Technically, the facility is comprised of a base-load WtE co-generation module, which may use MSW or biomass or a mix of them as input fuel, and a peak-load heat boiler, which is limited to biomass as input fuel, due to its inability to cope with the strict environmental standards related to MSW energy conversion. The decision maker decides which communities may supply their MSW, as well as which of the locally available biomass types will be included for consideration.

The multi-fuel concept is adapted from the multi-biomass model of Rentizelas et al. (2009) and is expanded to include the changes required to use both MSW and biomass as input fuels. More specifically, it should be noted that the MSW logistics is different than the biomass and 
is treated in a distinct manner. It is assumed that the WtE facility bears the cost of transporting the MSW from each centrally located municipal waste transfer station to the facility, since the MSW collection is currently performed by the local authorities. On the other hand, the facility bears the cost of all biomass logistics from collection and loading to transportation. Even more, MSW is an income source for the facility due to the gate fee charged to the municipalities for treatment/disposal, whereas biomass has a purchasing cost. Additionally, biomass may be used to increase the fuel mix heating value when MSW has a heating value lower than the critical one. The biomass prices are considered fixed, as it has been assumed that the facility operator will form long-term contracts with biomass and MSW suppliers. The concept explored in this work is to use MSW as a base-load fuel due to its relatively even supply, while satisfying peak-loads with biomass, which can be stored more efficiently and for longer time-periods.

In this model, the potential income from emissions reduction achieved is included. Emissions reduction may be credited for substituting conventional fuel generation of electricity, heat and cooling with renewable fuels and is calculated using the relevant approved methodology (UNFCCC-AM0025, 2012). The optimization method applied is a hybrid optimization method presented in Rentizelas et al. (2010).

Table 1. Notations

\begin{tabular}{lll}
\hline \multicolumn{2}{l}{ Sets and Indices } & Description \\
\hline$i$ & $i=1 \ldots n$ & Biomass type (including MSW) \\
$t$ & $t=1 \ldots T$ & Time period \\
$l$ & $l=1 \ldots L$ & Distance class from power plant \\
\hline Variables & Units & Description \\
\hline$B_{i l}$ & tn wet biom. & Annual amount of the $i^{\text {th }}$ biomass type to be procured from distance class $l$ \\
$P m h$ & $\mathrm{~kW}$ & Thermal capacity of the base-load MSW WtE plant \\
$P p$ & $\mathrm{~kW}$ & Thermal capacity of the peak-load biomass boiler \\
$V_{0}$ & $\mathrm{~m}^{3}$ & Initial annual biomass inventory \\
$X p$ & $\mathrm{~km}$ & Longitude of bioenergy facility (geographical coordinates in Hellenic \\
& & Geodetic Reference System - HGRS 87) \\
$Y p$ & $\mathrm{~km}$ & Latitude of bioenergy facility (geographical coordinates in Hellenic \\
& & Geodetic Reference System - HGRS 87) \\
\hline
\end{tabular}




\begin{tabular}{|c|c|c|}
\hline Parameters & Units & Description \\
\hline$C b_{i}$ & $€ /$ tn wet & Purchasing and loading cost of biomass type $i$ \\
\hline$C c$ & $€ / \mathrm{MWh}$ & Selling price of cooling \\
\hline Cch & $€ / \mathrm{kW}$ & Chiller specific investment cost \\
\hline$C_{\mathrm{CO} 2}$ & $€ /$ tn $\mathrm{CO} 2$ eq. & Market price of a ton $\mathrm{CO} 2$ equivalent \\
\hline$C d$ & $€ / \mathrm{m}$ & Main district heating pipeline specific investment cost \\
\hline$C d n$ & $€$ & Distribution network \& connection cost per district energy customer \\
\hline $\mathrm{Ce}$ & $€ / \mathrm{MWh}_{\mathrm{el}}$ & Selling price of electrical energy \\
\hline Cetf & $€$ & Fixed investment cost of electricity transmission line \\
\hline Cetv & $€ / \mathrm{km}$ & Variable investment cost of electricity transmission line \\
\hline$C h$ & $€ / \mathrm{MWh}$ & Selling price of heat \\
\hline $\mathrm{Cm}$ & $€ / \mathrm{kW}_{\mathrm{el}}$ & Specific investment cost of base-load unit \\
\hline$C_{M S W}$ & $€ /$ tn wet & Gate fee for MSW \\
\hline$C p$ & $€ / \mathrm{kW}$ & Specific investment cost of peak-load unit \\
\hline$C t d_{i}$ & $€ /\left(\mathrm{km}^{*} \mathrm{tn}\right)$ & Distance-specific transportation cost of biomass $i$ \\
\hline$C t t_{i}$ & $€ /(\mathrm{h} * \operatorname{tn})$ & Time-specific transportation cost of biomass $i$ \\
\hline$C w$ & $€ / \mathrm{m}^{2}$ & Specific investment cost for warehouse with drying capability \\
\hline Cwlc & $€ / \mathrm{m}^{2}$ & Specific investment cost for warehouse without drying capability \\
\hline $\bar{d}$ & $\mathrm{~kg} / \mathrm{m}^{3}$ & Mean biomass density \\
\hline$D f$ & - & Discounting coefficient \\
\hline$D_{l}$ & $\mathrm{~km}$ & Biomass transportation trip distance for class $l$ \\
\hline$E c_{t}$ & MWh & Cooling generated in period $t$ \\
\hline$E e_{t}$ & $\mathrm{MWh}_{\mathrm{el}}$ & Net electricity generated in period $t$ \\
\hline$E h_{t}$ & $\mathrm{MWh}$ & Equivalent heat demand of district energy consumers in period $t$ \\
\hline$E m h_{t}$ & MWh & Heat generated from the base-load CHP plant in period $t$ \\
\hline$E p h_{t}$ & MWh & Heat generated from the peak-load biomass boiler in period $t$ \\
\hline Ew & $\mathrm{m}^{2}$ & Warehouse area with (low cost) drying capability for safety stock \\
\hline Ewlc & $\mathrm{m}^{2}$ & Warehouse area without (low cost) drying capability for safety stock \\
\hline$f_{d}$ & - & Tortuosity factor (real travel distance/Euclidean distance) \\
\hline Gnet & tn $\mathrm{CO} 2 \mathrm{eq}$. & Net greenhouse gas (GHG) emissions reduction (UNFCCC-AM0025,2012) \\
\hline$H w$ & $\mathrm{~m}$ & Warehouse stocking height \\
\hline ir & $\%$ & Interest rate \\
\hline Iw & $€$ & Warehousing and related equipment investment cost \\
\hline$I_{l}$ & $€$ & Investment for biomass and waste loaders and related equipment \\
\hline$L d$ & $\mathrm{~m}$ & Length of main district heating pipeline \\
\hline Le & $\mathrm{km}$ & Length of electricity transmission line \\
\hline$\overline{L H V} m$ & $\mathrm{KJ} / \mathrm{kg}$ & Mean lower heating value of biomass \& MSW mix used for base-load unit \\
\hline Ls & $\mathrm{km}$ & Safety distance from heat $\&$ cooling consumers \\
\hline$m$ & $\%$ & Manoeuvring area coefficient for warehouse (total area/stocking area) \\
\hline$N$ & years & Investment lifetime \\
\hline $\mathrm{Nd}$ & - & Number of district energy customers \\
\hline ne & $\%$ & Electricity transmission losses \\
\hline$n m$ & $\%$ & Total efficiency factor of base-load WtE unit \\
\hline$n p$ & $\%$ & Total efficiency factor of peak-load unit \\
\hline$O M c$ & $€ /$ year & Operational \&Maintenance $(\mathrm{O} \& \mathrm{M})$ cost for Chilling equipment \\
\hline OMd & $€ /$ year & Operational \&Maintenance $(\mathrm{O} \& \mathrm{M})$ cost for District heating \\
\hline OMet & $€ /$ year & Operational \&Maintenance $(\mathrm{O} \& \mathrm{M})$ cost for Electricity transmission line \\
\hline$O M m$ & $€ /$ year & Operational \&Maintenance $(\mathrm{O} \& \mathrm{M})$ cost for Base-load unit \\
\hline$O M p$ & $€ /$ year & Operational \&Maintenance (O\&M) cost for Peak-load unit \\
\hline$O M w$ & $€ /$ year & Operational \&Maintenance $(\mathrm{O} \& \mathrm{M})$ cost for Warehousing \\
\hline Pch & $\mathrm{kW}$ & Chillers installed capacity \\
\hline PHR & - & Power-to-Heat ratio \\
\hline$P h d_{t}$ & $\mathrm{~kW}$ & Mean monthly equivalent thermal demand of customers \\
\hline Pme & $\mathrm{kW}_{\mathrm{el}}$ & Electrical capacity of the base-load CHP unit (=Pmh*PHR) \\
\hline
\end{tabular}




\begin{tabular}{lll}
$T_{l}$ & $\mathrm{~h}$ & return trip time for distance class $l$ \\
$V t$ & $\mathrm{~m} 3$ & Biomass \& Waste inventory in period t \\
$V s a f$ & $\mathrm{~m} 3$ & Biomass \& Waste safety stock \\
$X b_{l}$ & $\mathrm{~km}$ & Longitude of biomass fields belonging to $l$ distance class \\
$X d$ & $\mathrm{~km}$ & Longitude of heat \& cooling consumers \\
$X e$ & $\mathrm{~km}$ & Longitude of electricity connection point to grid \\
$Y b_{l}$ & $\mathrm{~km}$ & Latitude of biomass fields belonging to $l$ distance class \\
$Y d$ & $\mathrm{~km}$ & Latitude of heat \& cooling consumers \\
$Y e$ & $\mathrm{~km}$ & Latitude of electricity connection point to grid \\
$\varepsilon_{l}$ & $\%$ & District heating and cooling pipeline and network losses \\
$\rho$ & $\%$ & Inflation rate \\
\hline
\end{tabular}

\subsection{Objective Function.}

The objective function to be maximized is the Net Present Value (NPV) of the investment for the project's lifetime (before taxes). All the elements of the system are included in the investment analysis, i.e. the power plant, the supply chain of MSW and biomass, the district heating and cooling (district energy) network with the connection to the customers, as well as the electricity transmission line and connection to the grid. All operational costs are also taken into account. The NPV function to be maximized is presented in Eq. 1:

$$
\begin{aligned}
& \operatorname{MaxNPV}=\left[\sum_{i=M S W} \sum_{l} B_{i l} C_{M S W}+C e(1-n e) \sum_{t} E e_{t}+C h \sum_{t} E h_{t}+C c \sum_{t} E c_{t}+C c o_{2} G n e t\right] D f \\
& -[I w+C m P m h P H R+C p P p+C e t v L e+C e t f+C d L d+C d n N d+C c h P c h] \\
& -\left[\sum_{i \neq M S W} \sum_{l} B_{i l} C b_{i}+\sum_{i} \sum_{l} B_{i l}\left(C t d_{i} D_{l}+C t t_{i} T_{l}\right)+O M m+O M p+O M w+O M e t+O M d+O M c\right] D f
\end{aligned}
$$

where

$$
\begin{aligned}
& L e=\sqrt{(X p-X e)^{2}+(Y p-Y e)^{2}} \\
& L d=10^{3} \sqrt{(X p-X d)^{2}+(Y p-Y d)^{2}} \\
& D_{l}=\sqrt{f_{d}\left[\left(X p-X b_{l}\right)^{2}+\left(Y p-Y b_{l}\right)^{2}\right]} \quad \forall l \\
& B_{i}=\sum_{l=1}^{L} B_{i l}, \quad \forall i
\end{aligned}
$$


In Eq.1 the first group of terms in brackets refers to the revenue streams of the investment, the second group to the investment costs and the third group to the operational costs.

It should be noted that the warehousing investment cost $I w$ (Eq. 6) is related to the maximum yearly fuel inventory $\max V_{t}$, as this amount will determine the warehousing area required. It is assumed that two types of warehouses will be used: a warehouse with drying capabilities, which is able to hold and dry the fuel safety stock, and a lower cost warehouse structure without drying capabilities for the additional fuel quantities. The warehousing area is calculated in Eq. 7 for the former case and in Eq. 8 for the latter. It is assumed that fuel for the energy conversion unit is drawn from the safety stock warehouse, which is replenished by fuel from the lower cost warehouse. Therefore:

$$
\begin{aligned}
& I w=C w E w+C w l c E w l c+I_{l} \\
& E w=\frac{m^{*} V s a f}{H w} \\
& E w l c=m^{*}\left(\max V_{t}-V s a f\right) / H w
\end{aligned}
$$

All the annual monetary amounts are multiplied by an appropriate discounting coefficient $D f$ (Eq. 9), which turns them into present values, assuming that the annual amounts will be increased by the inflation rate $\rho$, which will remain fixed for the investment's lifetime:

$$
D f=\frac{1-\left[1+\frac{(i r-\rho)}{(1+\rho)}\right]^{-N}}{i r-\rho}
$$

\subsection{Optimization Variables.}

There are several independent variables that describe the system and are determined by the optimization method:

- $\quad X p \& Y p$ : The optimum location (geographical coordinates) of the facility. 
- Pmh: The thermal capacity of the base-load WtE plant. The electrical capacity of the plant (Pme) is assumed to be proportional to the thermal capacity.

- $\quad P p$ : The thermal capacity of the peak-load biomass boiler.

- $\quad B_{i}$ : The total amount of the $\mathrm{i}^{\text {th }}$ biomass type to be procured each year.

- $\quad V_{0}$ : The initial annual biomass inventory. This variable is necessary, as the calculations are based on a rolling horizon framework, similarly to Cundiff et al. (1997).

\subsection{Constraints.}

Several constraints have been introduced in the mathematical formulation of the problem. The first one (Eq. 10) requires that there should be enough biomass from all types apart from MSW to allow the operation of the biomass boiler, which cannot use MSW as fuel input:

$$
\sum_{i \neq M S W} L H V_{i} \sum_{l} B_{i l} \geq \frac{\sum_{t} E p h_{t}}{n p} \cdot 3.6 \cdot 10^{3}
$$

The second constraint (Eq. 11) states that the mean lower heating value $(\overline{L H V} m)$ of the fuel mix used in the base-load unit should exceed a critical minimum value for the safe operation of the power plant. If the fuel mix heating value is lower than the critical, it cannot be technically exploited in an incinerator, unless injection of a secondary fuel source (usually fossil fuel) is performed. In this work, biomass is used to increase the mean lower heating value of the MSW, if necessary. In the literature it has been proposed that the threshold value of $\overline{L H V} m$ should be $7 \mathrm{MJ} / \mathrm{kg}$ at an annual basis (World bank, 1999):

$\overline{L H V} m \geq L H V \min$

Another constraint (Eq. 12) is that the power plant must have enough capacity installed to satisfy the thermal or cooling peak loads of the consumers:

$P m h+P p \geq \max P h d_{t}$ 
where max $P h d_{t}$ is defined as the maximum thermal (or cooling) demand of the customers for a predefined confidence level, converted into equivalent heat demand. This constraint ensures that the installed heating power of the base-load MSW WtE unit and the peak-load biomass boiler will be sufficient to satisfy the thermal or cooling energy demand of the customers at all times.

The heat produced each time period by the base-load CHP unit and the peak-load boiler (in terms of energy) must satisfy at least the equivalent thermal energy demand of the DHC customers for every time period t (Eq. 13). It should be noted here that the equivalent thermal energy demand at the power plant side is increased by a percentage $\varepsilon_{l}$ to incorporate the heat losses incurred at the main district heating pipeline as well as the district heating distribution network.

$$
E m h_{t}+E p h_{t} \geq E h_{t}\left(1+\varepsilon_{l}\right), \mathrm{t}=1 \ldots \mathrm{T}
$$

Furthermore, there should be a fuel safety stock in the warehouse ( Vsaf) at any time to meet the energy needs of the customers for a certain timeframe, here assumed equal to seven days ( $T_{7}$ expressed in hours) of full-load operation for both base-load and peak-load units (Eq. 14):

$$
V_{t} \cdot \bar{d} \cdot \overline{L H V} \geq V s a f=3.6 \cdot 10^{3}\left(\frac{P m h(1+P H R)}{n m}+\frac{P p}{n p}\right) \cdot T_{7} \quad \forall t
$$

Another constraint is introduced (Eq. 15), due to the rolling horizon of the model (boundary constraint): The finishing season stock $\left(V_{T}\right)$ must be at least as much as the starting season stock $\left(V_{0}\right)$ :

$$
V_{T} \geq V_{0}
$$

The WtE power plant should not be located very close to the customers' location, which will probably be an inhabited area, due to potential local opposition (Upreti, 2004). In the facility location literature there exists a specific problem category, named semi-obnoxious or semi- 
desirable facility location, for facilities such as garbage dump sites, airports and power plants (Brimberg and Juel, 1998), where usually a bi-objective or multi-objective problem has to be solved. Here, the disservice generated by the $\mathrm{WtE}$ power plant has been treated as a constraint (Eq. 16), assuming that the $\mathrm{WtE}$ facility must be located at least a safety distance $(L s)$ away from the customers' location $(X d, Y d)$ to avoid potential local opposition:

$$
\sqrt{(X p-X d)^{2}+(Y p-Y d)^{2}} \geq L s
$$

The independent variables are required to be non-negative and upper bounds are also defined for many of them. For example, the annual amount of MSW and biomass is bounded by the maximum available quantity $\left(\max B_{i l}\right)$ in the distance class $l$ under examination (Eq. 17):

$$
0 \leq B_{i l} \leq \max B_{i l} \quad \forall i, l
$$

For security of supply reasons, the biomass boiler size has a lower bound equal to the minimum monthly heating and cooling demand of the final consumers, multiplied by a safety factor equal to 1.2 (Eq. 18). The underlying concept is that the boiler should be able to serve the heat and cooling demand at least for the month with the minimum demand, in order to allow maintenance of the main WtE unit without disrupting the energy supply of the consumers:

$P p \geq 120 \%$ min $P h d_{t}$

\section{Case study}

The case study region examined is a part of the district of Thessaly, close to the city of Larisa in Greece. The region has a significant number of inhabitants; therefore large amounts of MSW and several types of agricultural residue biomass are available, such as wheat straw, maize, cotton stalks and prunings from olive and almond trees. These biomass types have been characterized as dominant in the region, using Pareto analysis, and all of them are 
considered as potential fuel sources for the power plant. The district energy customer is the local community of Ampelonas, with about 1,900 households, identified to roughly match the expected energy generation of the available MSW quantities. The consumers are assumed to be currently using heating oil for space heating and electrical heat pumps for cooling. The facility will be planned to operate on heat-match mode. The investor could either be a private entity or a regional authority, and no subsidies of any kind have been included in the case study.

The revenue sources of the $\mathrm{WtE}$ facility under consideration are electricity sales to the national grid, heat and cooling supply to the customers via a district heating network as well as emissions reduction trading. The electricity produced will be sold directly to the national grid, at prices fixed by a contract with the Greek energy authority. The price of heat is assumed to be a fixed percentage $(80 \%)$ of the cost of heat using oil whereas the price of cooling is a fixed percentage $(80 \%)$ of the cost of electrical compression chillers, to provide citizens with a financial incentive to change their heating/cooling supply to the facility examined. Most of the agricultural biomass types included in the study have no current alternative use; therefore, it is assumed that they may be procured at low prices. It should also be mentioned that biomass degradation and material loss issues are neglected in this work. This assumption does not introduce a significant error if biomass is sufficiently dried and appropriately stored (Sanderson et al, 1997, Wiherssari, 2005), and since -in this workbiomass is not stored for the whole yearly period due to the multi-biomass concept used. Some of the most important case study parameter values are presented in Table 2 and Table 3.

Table 2. Main case study input data

\begin{tabular}{|c|c|}
\hline Parameter & Value Source \\
\hline
\end{tabular}




\begin{tabular}{|c|c|c|}
\hline Interest rate $(\%)$ & 8 & Rentizelas et al. (2009) \\
\hline Inflation (\%) & 3 & Rentizelas et al. (2009) \\
\hline Electricity selling price $(€ / \mathrm{MWh})$ & 105.4 & Feed-in tariff \\
\hline Heat selling price $(€ / \mathrm{MWh})$ & 90.8 & Calculated from oil price \\
\hline Cooling selling price $(€ / \mathrm{MWh})$ & 40 & Calculated from heat pump cost \\
\hline Oil price $(€ / \mathrm{kg})$ & 0.95 & Market price \\
\hline Investment lifetime (yr) & 20 & Rentizelas et al. (2009) \\
\hline Electrical efficiency of CHP unit (\%) & 23 & Consultation with experts \\
\hline Total efficiency of CHP unit (\%) & 85 & Consultation with experts \\
\hline Thermal efficiency of biomass boiler (\%) & 80 & Rentizelas and Tatsiopoulos (2010) \\
\hline $\begin{array}{l}\text { COP (Coefficient of Performance) of } \\
\text { absorption chillers }\end{array}$ & 0.7 & Rentizelas and Tatsiopoulos (2010) \\
\hline Electricity transmission losses (\% per km) & 0.2 & Consultation with experts \\
\hline $\begin{array}{l}\text { Fixed investment cost of electricity } \\
\text { transmission line }(€)\end{array}$ & 70,000 & Consultation with experts \\
\hline $\begin{array}{l}\text { Variable investment cost of electricity } \\
\text { transmission line }(€ / \mathrm{km})\end{array}$ & 30,000 & Consultation with experts \\
\hline O\&M of CHP unit (\% inv.cost/yr) & 5.5 & Consultation with experts \\
\hline O\&M of biomass boiler ( $\%$ inv.cost $/ \mathrm{yr}$ ) & 3 & Rentizelas and Tatsiopoulos (2010) \\
\hline $\begin{array}{l}\text { O\&M for Chilling equipment (\% } \\
\text { inv.cost/yr) }\end{array}$ & 2 & Consultation with experts \\
\hline $\begin{array}{l}\text { O\&M for Electricity transmission line (\% } \\
\text { inv.cost/yr) }\end{array}$ & 1.5 & Consultation with experts \\
\hline O\&M for Warehousing (\% inv.cost/yr) & 5 & Consultation with experts \\
\hline Tortuosity factor & 1.414 & Nilsson and Hansson (2001) \\
\hline
\end{tabular}

Table 3. Biomass and MSW-related case study input data

\begin{tabular}{|c|c|c|c|c|c|c|c|}
\hline & MSW & $\begin{array}{l}\text { Wheat } \\
\text { straw }\end{array}$ & $\begin{array}{l}\text { Corn } \\
\text { stalks }\end{array}$ & $\begin{array}{l}\text { Cotton } \\
\text { stalks }\end{array}$ & $\begin{array}{l}\text { Olive } \\
\text { tree } \\
\text { prunings }\end{array}$ & $\begin{array}{l}\text { Almond } \\
\text { tree } \\
\text { prunings }\end{array}$ & Source \\
\hline $\begin{array}{l}\text { Density wet - as } \\
\text { transported (kg/m3) }\end{array}$ & 367 & 140 & 200 & 200 & 250 & 300 & $\begin{array}{l}\text { Voivontas et al. } \\
\text { (2001), calculations } \\
\text { (MSW) }\end{array}$ \\
\hline Moisture wet (\%) & 40 & 20 & 50 & 30 & 35 & 40 & $\begin{array}{l}\text { Voivontas et al. } \\
\text { (2001), Komilis et al. } \\
\text { (2012) }\end{array}$ \\
\hline $\begin{array}{l}\text { Heating Value } \\
\text { (MJ/wet kg) }\end{array}$ & 8.5 & 14.9 & 12.3 & 15.1 & 13.4 & 13.1 & $\begin{array}{l}\text { Voivontas et al., } \\
\text { (2001), Papadopoulos } \\
\text { et al. (2002), Komilis } \\
\text { et al. (2012) }\end{array}$ \\
\hline Availability period & $\begin{array}{l}\text { All } \\
\text { year }\end{array}$ & $\begin{array}{l}\text { July- } \\
\text { Aug }\end{array}$ & $\begin{array}{l}\text { Nov- } \\
\text { Dec }\end{array}$ & $\begin{array}{l}\text { Oct- } \\
\text { Nov }\end{array}$ & Nov-Feb & Dec-Feb & $\begin{array}{l}\text { Consultation with } \\
\text { farmers }\end{array}$ \\
\hline $\begin{array}{l}\text { Price }(€ / \text { th wet }) \\
\text { [for MSW: Gate fee] }\end{array}$ & -50 & 50 & 20 & 20 & 30 & 30 & $\begin{array}{l}\text { Prices approximate, } \\
\text { consultation with } \\
\text { farmers and local } \\
\text { authorities }\end{array}$ \\
\hline
\end{tabular}




\section{Results}

The model application led to the optimum variable values (Table 4) as well as the respective financial criteria values (Table 5).

\section{Table 4. Optimum solution}

\begin{tabular}{lc}
\hline Parameter & Value \\
\hline WtE thermal capacity $\left(\mathrm{MW}_{\mathrm{th}}\right)$ & 19.091 \\
Biomass boiler thermal capacity $\left(\mathrm{MW}_{\mathrm{th}}\right)$ & 16.943 \\
Quantity MSW (tn/yr) & 87,821 \\
Biomass 1 Wheat straw (tn/yr) & 78 \\
Biomass 2 Corn stalks (tn/yr) & 0 \\
Biomass 3 Cotton stalks (tn/yr) & 5,156 \\
Biomass 4 Olive tree prunings (tn/yr) & 0 \\
Biomass 5 Almond tree prunings (tn/yr) & 1,092 \\
Initial biomass inventory (m $\left.{ }^{3}\right)$ & 8,176 \\
Facility longitude (km in HGRS87) & 359 \\
Facility latitude (km in HGRS87) & 4,398 \\
\hline
\end{tabular}

From the optimum solution one may see that the WtE facility will have a capacity of about 19 MW thermal, or equally 7 MW electrical. Furthermore, a 17 MW thermal biomass boiler will be required to deal with the thermal peak load. The energy conversion facility will be primarily using MSW as a fuel, utilising annually 87,821 tons, which is $96 \%$ of the total of 91,000 tons available at the regions included in the study. The rest of the fuel will be biomass comprised of 5,156 tons of cotton stalks, 1,092 tons of almond tree prunings and a small amount of wheat straw. The facility location, which has been determined by the optimization model, is presented in the map of Figure 1 as a blue mark. 


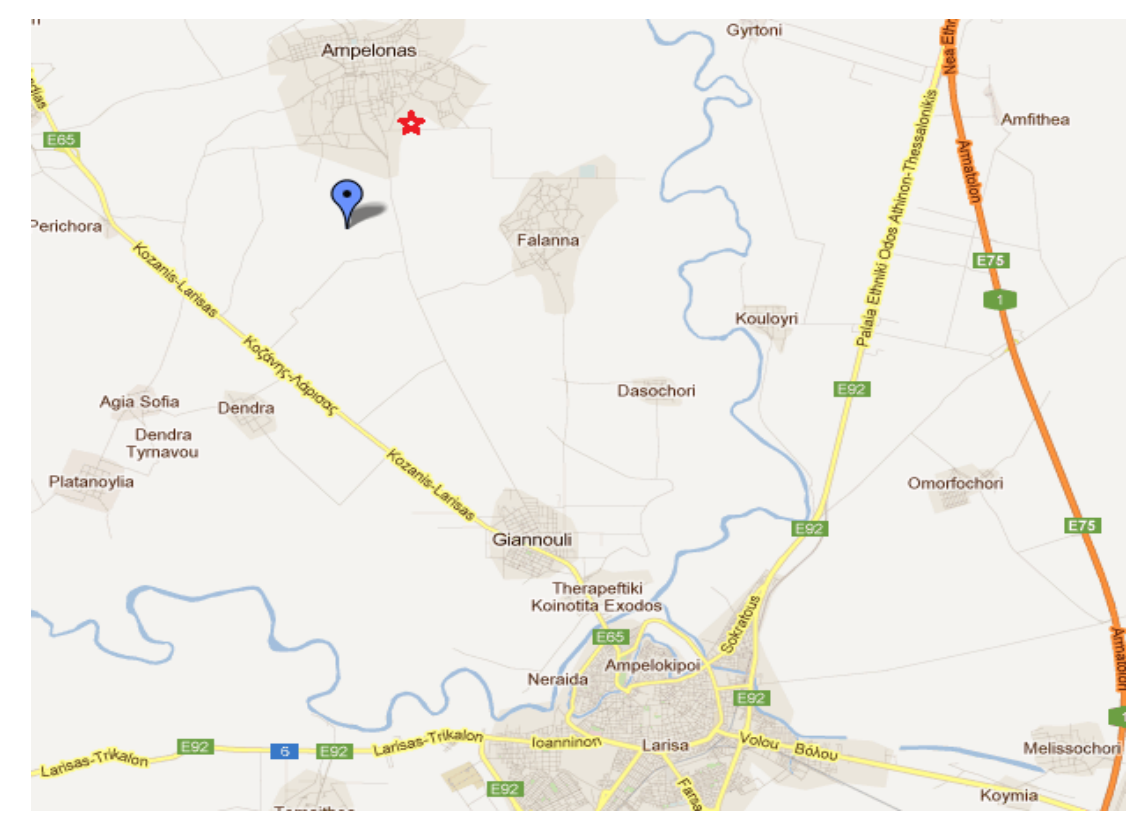

Figure 1. WtE facility location (blue mark) and heat demand customers (red star)

It is interesting to note that the $\mathrm{WtE}$ facility location is on the lower bound of the proximity constraint of the model (equal to $2 \mathrm{~km}$ ), obviously in order to reduce the investment cost and the energy losses of the district heating and cooling network. In reality, the calculated optimum facility location would serve as an indication for the interested investor to search a suitable site. The investor should also take into consideration other practical issues for the final siting of the facility at a later stage, such as availability of land around the optimal location, existing land uses, proximity to road network, access, cost of land etc. This argument is also supported by the findings of the sensitivity analysis (described in section 6 and Appendix A), where one might see that introducing stochastic values for certain critical parameters leads to alternative optimum facility locations, most of which lie in the close vicinity of the location presented in Table 4 and Figure 1.

Table 5. Financial criteria for the optimum solution

\begin{tabular}{ll}
\hline Criterion & Value \\
\hline NPV (Million Euros) & 102.603 \\
IRR (\%) & 22.78 \\
\hline
\end{tabular}




\begin{tabular}{ll}
\hline Pay Back Period (years) & 5.9 \\
\hline
\end{tabular}

The financial criteria of Table 5 suggest that the proposed investment is attractive with an expected NPV of around 102 million Euros within the 20-year operational period, an Internal Rate of Return (IRR) of $22.78 \%$ and Pay Back Period of approximately 6 years. The analysis results refer to an initial investment of about 69 million Euros. It should be noted here that the objective function optimizes based on the investment NPV, which means that solutions with higher value of IRR or lower Pay Back Period could be found by changing appropriately the objective function. It is also interesting to present the income and expense breakdown of the investment (Table 6).

Table 6. Income and expense breakdown for the optimum solution

\begin{tabular}{llll}
\hline Income Breakdown & & Expense Breakdown & \\
\hline MSW gate fee & $23.44 \%$ & Biomass purchasing & $1.35 \%$ \\
Electricity & $25.23 \%$ & Biomass \& MSW transportation & $2.35 \%$ \\
Heat & $30.67 \%$ & Warehousing & $5.69 \%$ \\
Cooling & $12.99 \%$ & WtE facility investment & $46.34 \%$ \\
Emissions reduction & $7.67 \%$ & WtE facility O\&M & $34.61 \%$ \\
& & Boiler investment & $1.14 \%$ \\
& & Boiler O\&M & $0.42 \%$ \\
& & Electricity transmission & $0.35 \%$ \\
& & District heating infrastructure & $3.78 \%$ \\
& & Cooling equipment & $3.98 \%$ \\
\hline
\end{tabular}

As far as the income sources are concerned, one may see that selling heat is the primary income source of the facility, providing about $30 \%$ of the total income. This is an immediate effect of the recent high increase of the oil price used for domestic heating in Greece.

Electricity and MSW gate fees are almost of equal importance for the facility, providing about $25 \%$ and $23 \%$ of the total income. Cooling sales contributes about $13 \%$ of the total income and finally, the income from emissions reduction trading could reach $7.7 \%$ of the total. The surprisingly much lower contribution of cooling sales as opposed to heat sales is due to the very efficient current alternative of using electric heat pumps for cooling with a high COP value, which determines a much lower unitary price for selling cooling energy (Table 2). 
As far as the expense streams are concerned, the primary cost factors are the investment and the operation and maintenance of the WtE facility, adding up to an $81 \%$ of the total system costs. This fact was expected, as these facilities have very high investment and operational cost to comply with the very strict emissions regulations. On the other hand, the biomass peak load boiler, which does not need such elaborate emissions control devices, is a low cost device responsible for $1.5 \%$ of the total cost. Infrastructure and equipment required for district heating and cooling contribute another $7.8 \%$ of the total cost, whereas the electricity transmission network is accountable for only $0.35 \%$. The biomass supply chain adds $1.35 \%$ of the total cost for biomass purchasing, which is very low due to the low quantities of biomass required. Furthermore, another $2.35 \%$ is added for biomass and MSW transportation and $5.7 \%$ for fuel warehousing, storage and handling.

It is also interesting to identify the optimum solution in the case that the facility was not eligible for emissions reduction trading as well as if the facility was operating only as cogeneration, meaning that only heat and electricity could be generated, but not cooling. The results are presented in Table 7, in comparison with the base case results analysed earlier. In the case of no trading of emissions reduction, the financial yield is affected negatively, but the optimization variables do not change significantly. However, the investment yield still remains satisfactory. The overall amount of fuel used is slightly higher in this scenario as a result of the slightly reduced capacity of the $\mathrm{WtE}$ facility, which has a higher efficiency, and the respectively increased capacity of the biomass boiler.

In the case of co-generation of electricity and heat, the model proposes that the MSW is not used as a fuel source at all, but only a biomass boiler is used to take advantage of the high heat prices connected to oil, which also means that no electricity is generated. The co- 
generation mode implies that the facility will operate only about half the year, when heat is required, and therefore a high investment such as the MSW WtE unit is not attractive. A lowcost biomass boiler may bring only half the NPV compared to the base case scenario; however, it is characterised by a much higher IRR and lower Pay Back Period due the combination of very low investment cost required, very high heating oil prices and low biomass cost assumed. This solution deviates though from the initial target of treating the MSW of the region. The facility location is not presented as it remains practically the same in all cases.

Table 7. Optimum solution for No GHG and CHP only scenarios

\begin{tabular}{llll}
\hline & Base Case & No GHG & CHP only \\
\hline WtE thermal capacity $\left(\mathrm{MW}_{\text {th }}\right)$ & 19.091 & 18.329 & 0 \\
Biomass boiler thermal capacity $\left(\mathrm{MW}_{\text {th }}\right)$ & 16.943 & 17.701 & 23.891 \\
Quantity MSW (tn/yr) & 87,821 & 89,599 & 0 \\
Biomass 1 Wheat straw (tn/yr) & 78 & 0 & 0 \\
Biomass 2 Corn stalks (tn/yr) & 0 & 0 & 0 \\
Biomass 3 Cotton stalks (tn/yr) & 5,156 & 6,101 & 5,417 \\
Biomass 4 Olive tree prunings (tn/yr) & 0 & 0 & 2,702 \\
Biomass 5 Almond tree prunings (tn/yr) & 1,092 & 1,028 & 12,855 \\
Initial biomass inventory (m $\left.{ }^{3}\right)$ & 8,176 & 50,000 & 9,585 \\
NPV (Million Euros) & 102.603 & 84.824 & 53.188 \\
IRR (\%) & 22.78 & 20.57 & 67.68 \\
Pay Back Period (years) & 5.9 & 6.71 & 1.70
\end{tabular}

All the results presented in this study concern cash flows before taxes. This approach has been adopted to provide results that are globally applicable, as taxation is an issue treated differently among countries and may change depending on the timing of the investment, specific incentives etc. However, in order to provide an indication of its effect, a scenario has been examined incorporating the effect of taxation of profits on the financial yield of the optimal solution of the Base Case scenario, based on the current tax conditions in Greece: the tax rate has been assumed equal to $25 \%$ and a mean depreciation factor of $7 \%$ has been adopted. The results are presented in Table 8, together with the Base Case scenario results. 
Table 8. Effect of taxation on the financial yield of the investment

\begin{tabular}{lll}
\hline & $\begin{array}{l}\text { Base Case } \\
\text { (before taxes) }\end{array}$ & After taxes \\
\hline NPV (Million Euros) & 102.603 & 73.643 \\
IRR (\%) & 22.78 & 19.22 \\
\hline
\end{tabular}

It is interesting to note that still after application of taxes the NPV remains positive, though it is significantly reduced (by about $28.2 \%$ ). The IRR of the investment is also reduced significantly (by $3.56 \%$ ). The investment is still considered as profitable, even after incorporating the taxes effect.

\section{Sensitivity analysis}

Due to the fact that most parameters included in the model have a degree of uncertainty, a sensitivity analysis of the optimum solution has been performed in relation to the most important financial parameters. A $10 \%$ increase of the base-case value of each parameter has been assumed and the resulting change in the NPV value of the investment is presented in Figure 2. 


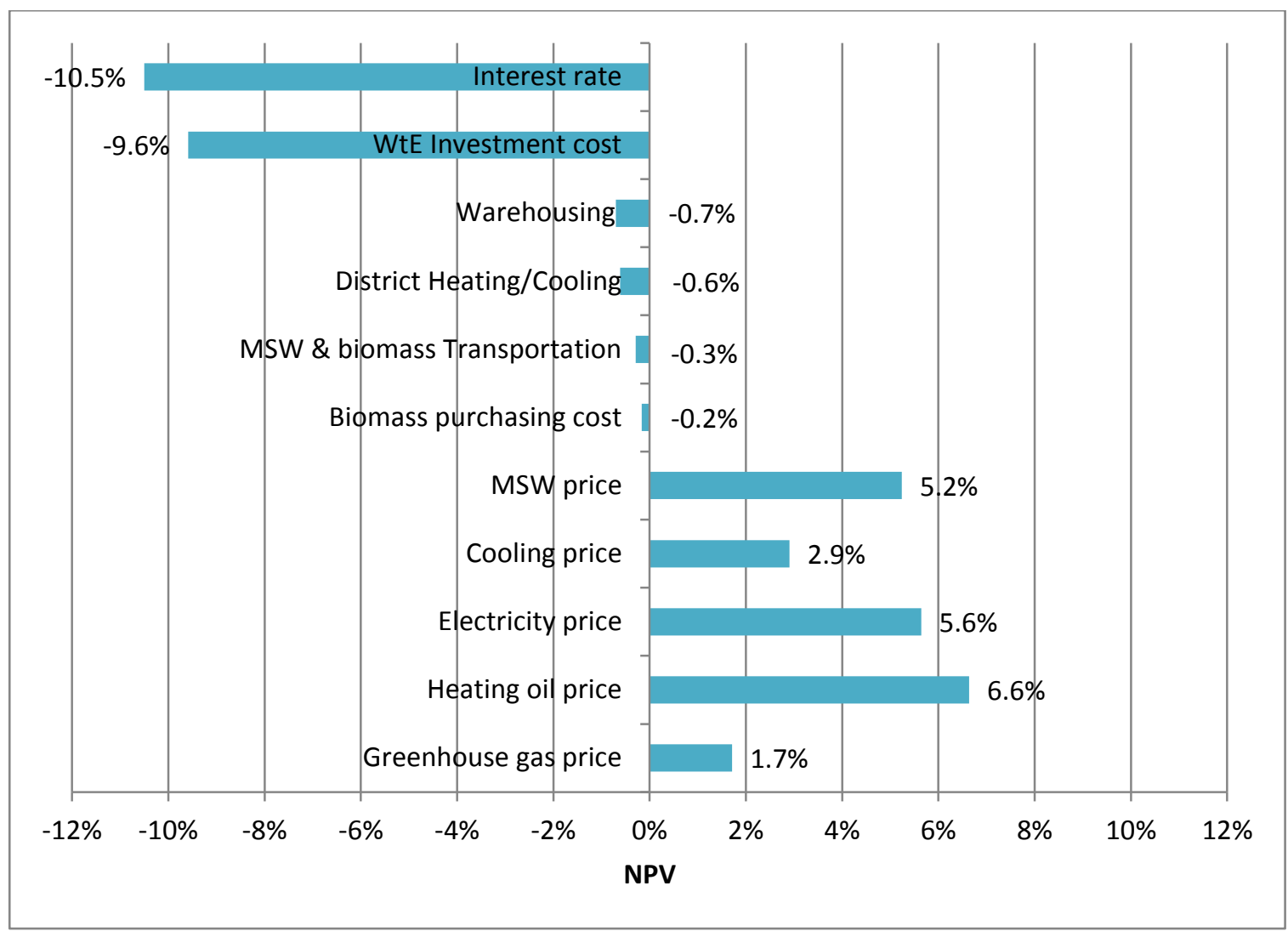

Figure 2. NPV change for a $10 \%$ increase of each parameter's value

It is interesting to note that the $\mathrm{WtE}$ facility investment cost has a very significant impact on the NPV, as a $10 \%$ increase of this cost leads to almost $10 \%$ reduction of the NPV. Therefore, potential investors should be very careful in costing the facility, as the construction costs of such facilities range significantly in the relevant literature and are also dependent on the local conditions and MSW management structure as well as on the MSW composition. The interest rate fluctuation has an even higher impact on the financial yield, as a $10 \%$ increase would result in $10.5 \%$ reduction of the project NPV. Consequently, sources of project funding and means to reduce the relative interest rate should be a major concern of the investors.

Other cost categories seem to have minor effect on the profitability of the investment. For example, a $10 \%$ increase of warehousing-related costs would reduce the NPV by $0.7 \%$, whereas similar increase of the district heating and cooling (DHC) network investment and 
operational cost, would reduce the NPV by $0.6 \%$. Nevertheless, the minor effect of the DHC network is primarily a result of the optimization of the system, which leads to a minimum length (and therefore low-cost) pipeline required. In case of a requirement for longer network construction, its effect on the project NPV would be almost proportionally increased. The potential increase of transportation fuel cost (MSW and biomass) has a very limited effect on the project investment yield. This is a result of the plant location optimization, the small quantities of biomass procured and the fact that the system examined performs only part of the MSW transportation function. Biomass purchasing cost has a negligible negative effect on the NPV, as it is only a small fraction of the total fuel used.

As far as the prices of the $\mathrm{WtE}$ facility products are concerned, a change in the heating oil price seems to bear the most significant change in the NPV (6.6\%). An increase of heating oil price has a dual effect: on the one hand the heat may be sold at a higher price, as it has been assumed that it is always priced at $80 \%$ of the cost of using heating oil, and on the other hand it increases the cost of transporting and handling biomass and MSW, as the related equipment use diesel oil, which follows the fluctuations of heating oil price. It is obvious though that the former effect is dominating. An electricity price increase by $10 \%$ leads to a $5.6 \%$ increase of the NPV value, whereas the MSW gate fee follows closely, leading to a $5.2 \%$ increase of the NPV. A $10 \%$ increase of the cooling price and of the ton $\mathrm{CO} 2$ equivalent price lead to $2.9 \%$ and $1.7 \%$ increase of the NPV respectively. Therefore, the interested investors should pay careful attention to the potential fluctuation of future oil prices, as they have a strong effect on the yield of the investment. Electricity prices are usually fixed via long-term contracts with the grid operator for renewable source energy (feed-in-tariff), and thus present no risk for the investment. MSW gate fee has also a significant effect; therefore one should focus on securing its value with long-term contracts, which should probably offer safety over the potential fluctuations of future oil prices. It should be noted here that the effect of the MSW 
price is more significant than that of the biomass price. The reasons are that the annual quantities of MSW are one order of magnitude larger and the MSW unitary value is higher. Finally, the greenhouse gas value has fluctuated tremendously over the past few years, and therefore its future value is very difficult to predict.

Some of the most critical parameters that influence the optimum solution of this model, such as the price of electricity, the price of heating oil and the price of a ton $\mathrm{CO} 2$ equivalent, as well as the heating and cooling demand of the customers, are actually stochastic parameters that are characterised by significant variability. For this reason, a stochastic approach has been adopted for determining the effect of the variation of these parameters on the robustness of both the model and the solution. The results of the stochastic analysis are presented in Appendix A.

\section{Conclusions}

This work is concerned with the issue of using MSW as a fuel source for energy conversion. A model is presented that examines the case of using mixed MSW and agricultural biomass in the same energy conversion facility, by simulating the processes of MSW and biomass logistics, energy conversion and supply of the energy products to the consumers. The energy products included in the study are electricity, heat and cooling (tri-generation), as this strategy presents advantages for regions with warm climates. The system simulated is optimized in terms of basic design characteristics (location of the facility and capacities of base-load and peak-load units) as well as operational parameters (annual amounts of each fuel type). The optimization criterion is the NPV of the investment.

The model has been applied to a case study, which is a rural area in the prefecture of Thesally, Greece. The results show that the investment for a tri-generation facility that will use almost 
the entire available MSW amount of the municipalities included in the study is financially attractive, even with the modest assumption of a MSW gate fee of $50 € / \mathrm{tn}$. Currently, the mean landfill gate fee in Greece is $25 € / \mathrm{tn}$, one of the lowest in the EU, and there is no landfill tax added (EEA, 2013). However, according to the EEA (2013) the landfill tax alone will soon be between 50-70 €/tn in many EU countries, therefore increasing the total cost of landfilling.

The most important income source is heat sales, followed by electricity sales and MSW gate fee. The sensitivity analysis results identify important critical factors that should be considered before deciding to proceed with such an investment. Heat sales is the major income-related parameter influencing the financial yield of the investment. This fact, combined with the significant fluctuations of oil price lately, indicates that a potential investor should be very careful in estimating both future prices of oil as well as quantities of heat sales. On the cost side, the interest rate and the investment cost of the MSW WtE unit seem to be very influential parameters, which may easily change the financial outlook of the investment, and therefore require close attention.

The robustness of the solution has been examined using a stochastic sensitivity analysis for the most crucial parameters, which are the electricity price, oil price, ton $\mathrm{CO} 2$ equiv. price and the heating and cooling monthly demand (Appendix A). The results of the stochastic sensitivity analysis show that the optimum solution found is fairly robust concerning the CHP size, the plant location and the proportions of each fuel type to be used. However, the boiler size was found to present higher variance, especially in the case of stochastic heat/cooling demand. Apart from the latter case, in all other cases the mean values of the normal distributions fitted to the results of the stochastic analysis lie closely to the optimum values determined by the model. 
The investment remains financially attractive even if it is not eligible for trading its emissions reduction achieved. It also remains financially attractive even after examining the effect of taxes on the cash flows of the investment, though the yield is significantly reduced. Finally, if only co-generation is considered, it would be much more efficient in terms of investment yield to construct only a biomass boiler using solely biomass as a fuel source.

\section{References}

Bordonaba, J.G, Vilavert, L, Nadal, M, Schuhmacher, M, Domingo, J.L., 2011. Monitoring environmental levels of trace elements near a hazardous waste incinerator human health risks after a decade of regular operations. Biol Trace Elem Res. 144, 1419-29.

Barton, J.R., Issaias, I., Stentiford, E.I., 2008. Carbon - Making the right choice for waste management in developing countries. Waste Manag. 28, 690-698.

Brimberg, J., Juel, H., 1998. A bicriteria model for locating a semi-desirable facility in the plane. Eur J Oper Res. 106 (1), 144-151.

CEWEP - Confederation of European waste-to-energy plants, 2011. Available from: http://www.cewep.eu/index.html, [accessed 14/11/2011].

Cundiff, J.S., Dias, N., Sherali, H.D., 1997. A linear programming approach for designing a herbaceous biomass delivery system. Bioresour Technol. 59 (1), 47-55.

Demirbas, M. F., Balat, M., Balat, H. 2009. Potential contribution of biomass to the sustainable energy development. Energy Convers Manag. 50 (7), 1746-1760.

Dornburg, V., Faaij, A. P. C., Meuleman, B. 2006a. Optimising waste treatment systems: Part A: Methodology and technological data for optimising energy production and economic performance. Resour Conserv and Recycl. 49 (1), 68-88.

Dornburg, V., Faaij, A. P. C. 2006b. Optimising waste treatment systems: Part B: Analyses and scenarios for The Netherlands. Resour Conserv and Recycl. 48 (3), 227-248. 
EEA - European Environment Agency. 2013. Managing municipal solid waste - a review of achievements in 32 European countries. EEA Report No2/2013.

EPA - United States Environmental Protection Agency, 2011. Available from: http://www.epa.gov/cleanenergy/energy-and-you/affect/municipal-sw.html [accessed 12/11/2011]

European Commission, 2006, Waste Incineration - Integrated pollution prevention and control - Reference document on the Best Available Techniques, August 2006.

Eurostat, 2011. Statistics in focus - Environment and energy: Generation and treatment of municipal waste, Available from:

http://epp.eurostat.ec.europa.eu/cache/ITY_OFFPUB/KS-SF-11-031/EN/KS-SF-11-031EN.PDF [accessed 5/9/2013]

Freppaz, D., Minciardi, R., Robba, M., Rovatti, M., Sacile, R., Taramasso, A., 2004. Optimizing forest biomass exploitation for energy supply at a regional level. Biomass Bioenerg. 26 (1), 15-25.

Fruergaard, T., Astrup, T. 2011. Optimal utilization of waste-to-energy in an LCA perspective. Waste Manag. 31 (3), 572-82.

Kathirvale, S., Yunus, M.M., Sopian, K., Samduddin, A.H., 2003. Energy potential from municipal solid waste in Malaysia. Renew Energy. 29 (4), 559-567.

Komilis, D., Evangelou, A., Giannakis, G., Lymperis, C. 2012. Revisiting the elemental composition and the calorific value of the organic fraction of municipal solid wastes. Waste Manag. 32 (3), 372-381.

Koukouzas, N., Katsiadakis, A., Karlopoulos, E., Kakaras, E., 2008. Co-gasification of solid waste and lignite - A case study for Western Macedonia. Waste Manag. 28 (7), 1263-1275.

Laryea-Goldsmith, R., Oakey, J., Simms, N., 2011. Gaseous emissions during concurrent combustion of biomass and non-recyclable municipal solid waste. Chem Cen J, 5 (4). 1-10. 
Luoranen, M., Horttanainen, M., 2007. Feasibility of energy recovery from municipal solid waste in an integrated municipal energy supply and waste management system. Waste Manag Res. 25, 426-439.

McKay, G., 2002. Dioxin characterisation, formation and minimisation during municipal solid waste (MSW) incineration: review. Chem Eng J. 86 (3), 343-68.

Morselli, L, Passarini, F, Piccari, L, Vassura, I, Bernardi, E., 2011. Risk assessment applied to air emissions from a medium-sized Italian MSW incinerator. Waste Manag Res. 29, 48-56.

Münster, M., Lund, H. 2010. Comparing Waste-to-Energy technologies by applying energy system analysis. Waste Manag. 30 (7), 1251-63.

Münster, M., Meibom, P. 2011. Optimization of use of waste in the future energy system. Energy. 36 (3), 1612-1622.

Nagel, J., 2000. Determination of an economic energy supply structure based on biomass using a mixed-integer linear optimization model. Ecol Eng. 16, 91-102.

Nilsson, D., 1999. SHAM--a simulation model for designing straw fuel delivery systems. Part 1: model description. Biomass Bioenerg. 16 (1), 25-38.

Nilsson, D., Hansson, P., 2001. Influence of various machinery combinations, fuel proportions and storage capacities on costs for co-handling of straw and reed canary grass to district heating plants. Biomass Bioenerg. 20, 247-60.

Nowak, P., Gehrmann, H.J., Maier, J., Pfrang-Stotz, G., Paur, H.R., Seifert, H., Glorius, T., 2012. Co-firing of Solid Recovered Fuels with biomass in grate firings. Int J Chem Environm Eng Syst. 3 (2), 42-52.

Papadopoulos, D.P., Katsigiannis P.A., 2002. Biomass energy surveying and technoeconomic assessment of suitable CHP system installations. Biomass Bioenergy. 22 (2), 105-124. 
Perkoulidis, G., Papageorgiou, A., Karagiannidis, A., Kalogirou, S., 2010. Integrated assessment of a new Waste-to-Energy facility in Central Greece in the context of regional perspectives. Waste Manag. 30 (7), 1395-1406.

Porteous, A., 2001. Energy from waste incineration — a state of the art emissions review with an emphasis on public acceptability. Appl Energy. 70 (2), 157-67.

Ramzan, N., Ashraf, A., Naveed, S., Malik, A., 2011. Simulation of hybrid biomass gasification using Aspen plus: A comparative performance analysis for food, municipal solid and poultry waste. Biomass . Bioenerg, 35 (9), 3962-3969,

Rentizelas, A., Tatsiopoulos, I.P., Tolis, A., 2009. An Optimization Model for Multi-biomass Tri-generation Energy Supply. Biomass Bioenerg. 33 (2), 223-233.

Rentizelas, A., Tatsiopoulos, I.P., 2010. Locating a bioenergy facility using a hybrid optimization method. Int J Prod Econ. 123 (1), 196-209.

Sanderson, M.A., Egg, R.P. and Wiselogel, A.E. 1997. Biomass losses during harvest and storage of switchgrass, Biomass Bioenerg. 12 (2), 107-114.

Singh, R.P., Tyagi, V.V., Allen, T., Hakimi Ibrahim, M., Kothari, R. 2011. An overview for exploring the possibilities of energy generation from municipal solid waste (MSW) in Indian scenario, Renew Sust Energ Rev. 15 (9), 4797-4808.

Tatsiopoulos, I.P., Tolis A J., 2003. Economic aspects of the cotton-stalk biomass logistics and comparison of supply chain methods. Biomass Bioenerg. 24 (3), 199-214.

UNFCCC-AM0025, 2012. Approved baseline and monitoring methodology AM0025: Avoided emissions from organic waste through alternative waste treatment processes. version 13.0.0, United Nations Framework Convention on Climate Change -CDM Executive Board

Unnikrishnan, S., Singh, A., 2010. Energy recovery in solid waste management through CDM in India and other countries. Resour Conserv and Recycl. 54 (10), 630-640. 
Upreti, B.R., 2004. Conflict over biomass energy development in the United Kingdom: Some observations and lessons from England and Wales. Energy Policy. 32 (6), 785-800.

Voivontas, D., Assimacopoulos, D., Koukios, E.G., 2001. Assessment of biomass potential for power production: A GIS based method. Biomass Bioenerg. 20 (2), 101-112.

Wihersaari, M. 2005. Evaluation of greenhouse gas emission risks from storage of wood residue. Biomass Bioenerg. 28 (5), 444-453.

World Bank, 1999. Technical guidance report: Municipal Solid Waste Incineration, The World Bank, Washington D.C.

Xie, H.W. Zhang, Y. 2013. Experimental study on the co-firing power generation of municipal solid waste and biomass. Appl Mech Mat. 280, 291-294. 


\section{Figure Captions}

Figure 1: WtE facility location (blue mark) and heat demand customers (red star)

Figure 2: NPV change for a 10\% increase of each parameter's value

Figure A.1. NPV distribution with stochastic parameters

Figure A.2. CHP unit size distribution with stochastic parameters

Figure A.3. Boiler size distribution with stochastic parameters 


\section{Appendix A}

The parameters that influence the optimum solution of the model and are stochastically analysed, are the price of electricity, the price of heating oil, the price of a ton $\mathrm{CO} 2$ equivalent, as well as the heating and cooling demand of the customers. Actually, electricity price in renewable energy investments is currently fixed via long-term contracts and therefore presents no significant risk for the investors; nevertheless, its effect on the optimum solution has been examined as if it were subject to the same variability as the electricity system marginal price for fossil-fuel electricity generators to devise some conclusions of what would happen if the feed-in-tariff scheme ceased to exist in the future.

The statistical distributions of the parameters used for the stochastic analysis have been devised by fitting distributions in past data and are presented in Table A.1. The normal distributions concerning the heating and cooling demand of the customers are not presented due to lack of space, as the distribution fitted is different for each month of the year.

Table A.1. Statistical distributions for critical parameters

\begin{tabular}{|c|c|c|c|}
\hline & $\begin{array}{l}\text { Electricity price } \\
\text { (€/MWh) }\end{array}$ & $\begin{array}{l}\text { Oil price } \\
(€ / \mathbf{k g})\end{array}$ & $\begin{array}{l}\text { Ton CO2 equiv. } \\
\text { price }(€ / \text { ton } \\
\text { CO2) }\end{array}$ \\
\hline \multirow[t]{2}{*}{ Distribution } & $\begin{array}{l}\text { Generalized } \\
\text { Extreme Value }\end{array}$ & Normal & Lognormal \\
\hline & $\begin{array}{l}\text { Location parameter } \\
\mu=95\end{array}$ & $\begin{array}{l}\text { Mean } \\
\mu=0.95\end{array}$ & $\begin{array}{l}\text { Mean of } \ln (X) \\
\mu=2.3011\end{array}$ \\
\hline \multirow[t]{2}{*}{$\begin{array}{l}\text { Distribution } \\
\text { Characteristics }\end{array}$} & $\begin{array}{l}\text { Scale parameter } \\
\sigma=14.4256\end{array}$ & $\begin{array}{l}\text { Standard } \\
\text { Deviation } \\
\sigma=0.0346\end{array}$ & $\begin{array}{l}\text { Standard } \\
\text { Deviation of } \ln (\mathrm{X}) \\
\sigma=0.0547\end{array}$ \\
\hline & $\begin{array}{l}\text { Shape parameter } \\
\xi=0.1271\end{array}$ & & \\
\hline
\end{tabular}

The results obtained concern a thousand iterations of the model for each stochastic parameter and distributions have been fitted to the results in order to increase legibility of the findings. 


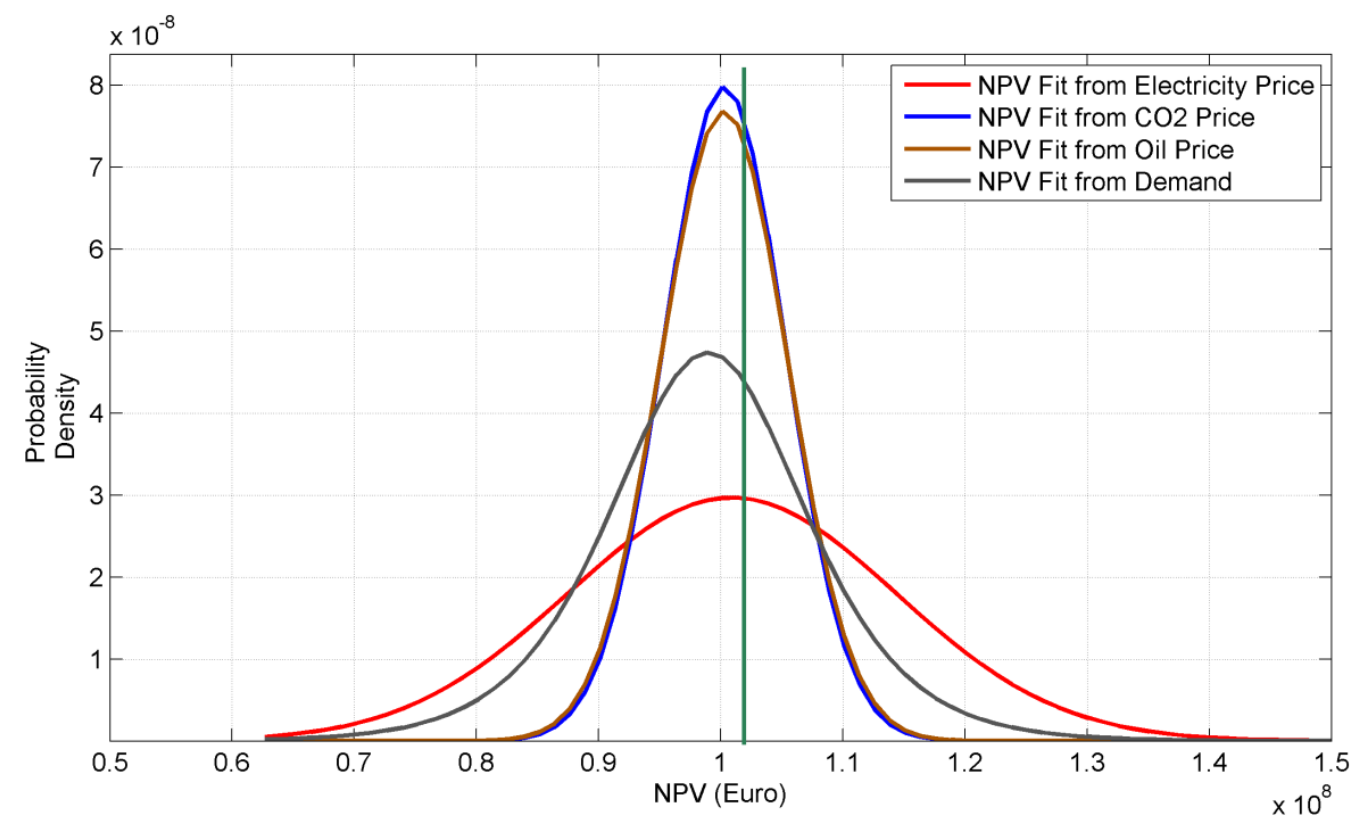

Figure A.1. NPV distribution with stochastic parameters

In Figure A.1, the distribution of the NPV may be seen. It is interesting to note that the expected mean value of the normal distributions fitted is very close to the one calculated in the original solution of Table 5 (presented as a solid line). The variance of the NPV is limited for the ton $\mathrm{CO} 2$ price equiv. and oil price, whereas the demand fluctuation leads to a higher variance. The highest variance is reported for the price of electricity. Therefore, it can be inferred that the robustness of the solution's NPV is mostly affected by the electricity price. It should be noted though that it is expected for the NPV to change when changing the prices of the energy products generated. Furthermore, changing the heating and cooling demand usually leads to a different unit size and setup, therefore to a different solution.

In order to examine the robustness of the variable values concerning the system design, the distributions of the CHP unit size and Boiler unit size are presented in Figures A.2 and A.3. 


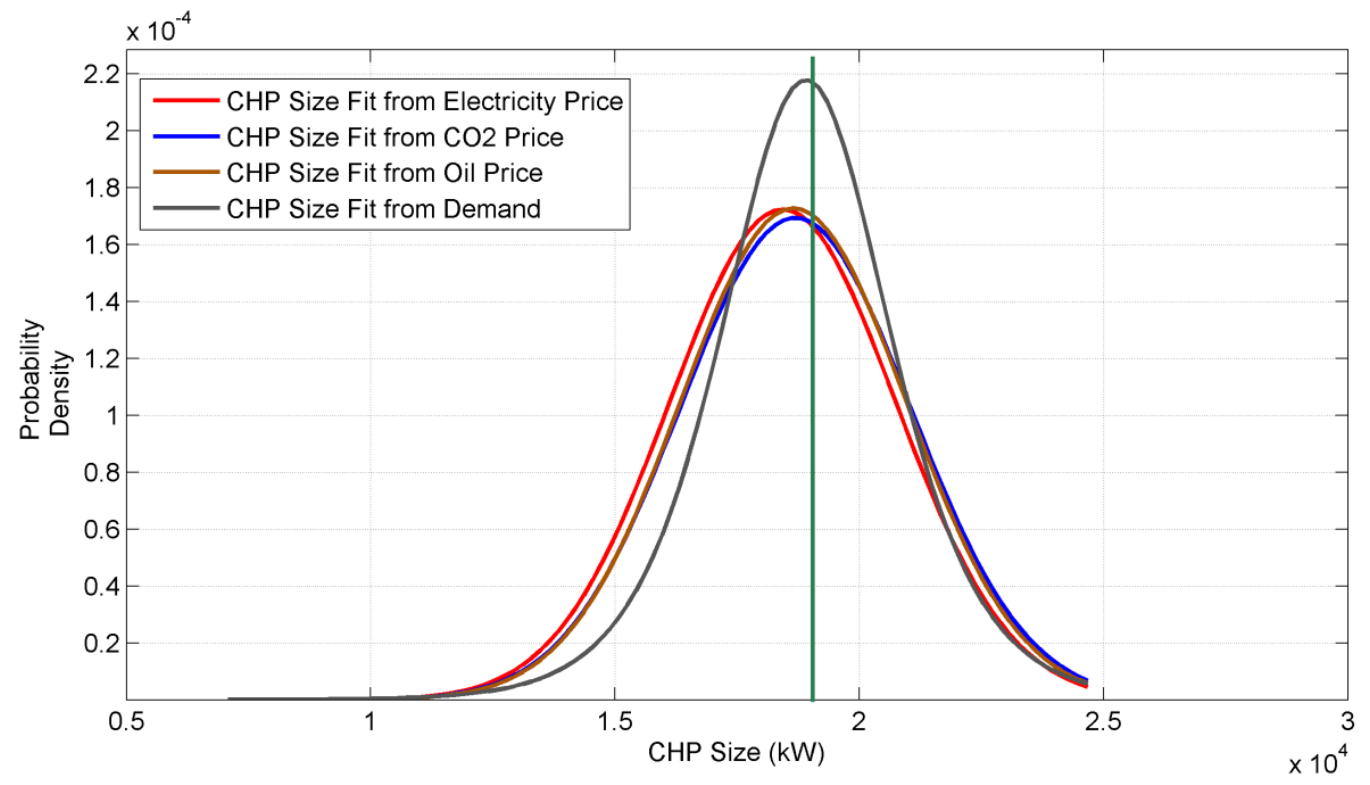

Figure A.2. CHP unit size distribution with stochastic parameters

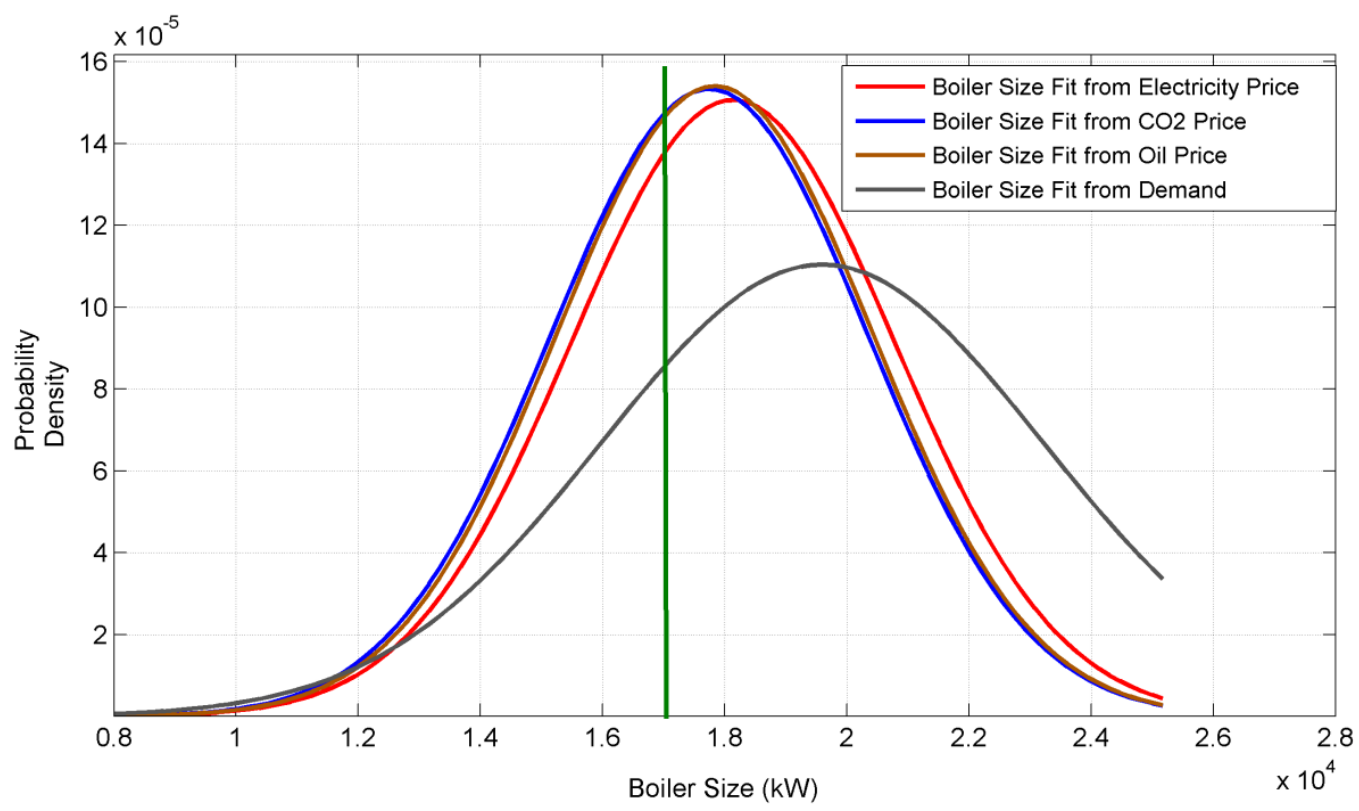

Figure A.3. Boiler size distribution with stochastic parameters

It can be inferred that for electricity, oil and ton $\mathrm{CO} 2$ equiv. prices the mean value of the distributions fitted is very close to the original values of the optimum solution, which are presented as solid lines in Figures A.2 and A.3. The variance of the CHP unit and the Boiler sizes is almost identical in all cases apart from demand fluctuations, and it can be characterised as significant. This means that changing the value of these parameters leads to a 
different optimum plant size. However, the most frequent value for plant sizes encountered is the one originally calculated, which is an indication that choosing this specific size bears the most chances of adopting the optimum solution in an uncertain environment. It is obvious that the solutions concerning the size of CHP unit are more robust compared to those of the Boiler unit, as they are characterized by significantly lower variance. Specifically for the heating or cooling demand fluctuations case, the CHP size is less sensitive to changes than the boiler size. This finding implies that the variability of demand mainly affects the boiler size, which is used to cover the thermal and cooling peak-loads.

It is also interesting to examine the effect of uncertainty of the aforementioned parameters to the optimum plant location calculated, as locating the facility is one of the major strategic decisions the investor has to make. In Table A.2, the proximity of the locations derived from using stochastic parameter values to the original optimum location of Table 4 is presented. The results show that in about $64 \%$ to $67 \%$ of the cases examined, the location proposed by the stochastic analysis lies within a circle of radius equal to $500 \mathrm{~m}$ around the original location proposed. This is an indication that the model solution is fairly robust concerning the plant location. It also supports the argument raised earlier in this paper that the potential investor would have to identify a suitable location for siting the facility as close as possibly to the original optimum location calculated and no further than $500 \mathrm{~m}$ from it, as this appears to be the optimum location even if the parameters' values are uncertain.

Table A.2. Plant location with stochastic parameters compared to original optimum location.

\begin{tabular}{lrrrrr}
\hline $\begin{array}{l}\text { Distance from } \\
\text { optimum location } \\
\text { (km) }\end{array}$ & $\begin{array}{l}\text { Electricity } \\
\text { Price }\end{array}$ & $\begin{array}{l}\text { CO2 } \\
\text { price }\end{array}$ & $\begin{array}{l}\text { Fuel } \\
\text { price }\end{array}$ & Demand \\
\hline 0.5 & $67.7 \%$ & $64.4 \%$ & $65.1 \%$ & $66.4 \%$ \\
1 & $5.6 \%$ & $6.0 \%$ & $6.3 \%$ & $7.4 \%$ \\
1.5 & $6.0 \%$ & $7.6 \%$ & $4.9 \%$ & $5.3 \%$ \\
2 & $3.4 \%$ & $4.7 \%$ & $5.5 \%$ & $3.2 \%$ \\
2.5 & $3.9 \%$ & $2.9 \%$ & $4.7 \%$ & $3.2 \%$ \\
\hline
\end{tabular}




\begin{tabular}{rrrrr}
\hline 3 & $2.8 \%$ & $3.8 \%$ & $2.3 \%$ & $3.6 \%$ \\
3.5 & $3.2 \%$ & $2.7 \%$ & $3.0 \%$ & $4.7 \%$ \\
4 & $3.7 \%$ & $3.6 \%$ & $2.7 \%$ & $3.2 \%$ \\
4.5 & $1.5 \%$ & $1.6 \%$ & $3.6 \%$ & $2.2 \%$ \\
5 & $2.2 \%$ & $2.9 \%$ & $1.9 \%$ & $1.0 \%$ \\
\hline
\end{tabular}

As far as the fuel types and quantities to be used are concerned, the results are presented in

Table A.3 in the form of fitted normal distributions due to the complexity of the data.

Table A.3. Quantities of each fuel type with stochastic parameters

\begin{tabular}{lrrrrr}
\hline Fuel type & & $\begin{array}{l}\text { Electricity } \\
\text { Price }\end{array}$ & $\begin{array}{l}\text { CO2 } \\
\text { price }\end{array}$ & \multicolumn{1}{l}{$\begin{array}{l}\text { Fuel } \\
\text { price }\end{array}$} & Demand \\
\hline MSW (tn/yr) & Mean & $87,545.8$ & $87,440.1$ & $87,420.4$ & $86,923.3$ \\
& St. dev & $8,818.0$ & $8,948.6$ & $8,564.2$ & $8,151.0$ \\
Biomass 1 Wheat & Mean & 219.1 & 268.3 & 264.2 & 232.1 \\
straw (tn/yr) & St. dev & 837.2 & 878.6 & 805.7 & 798.5 \\
Biomass 2 Corn & Mean & 459.4 & 375.7 & 550.3 & 398.6 \\
stalks (tn/yr) & St. dev & $1,274.9$ & $1,232.6$ & $1,569.9$ & $1,119.7$ \\
Biomass 3 Cotton & Mean & $3,716.9$ & $4,755.8$ & $4,553.9$ & $4,190.8$ \\
stalks (tn/yr) & St. dev & $4,030.0$ & $3,793.1$ & $3,709.5$ & $3,975.8$ \\
Biomass 4 Olive tree & Mean & 366.8 & 377.8 & 426.0 & 395.7 \\
prunings (tn/yr) & St. dev & $1,077.5$ & $1,003.7$ & $1,138.2$ & $1,127.7$ \\
Biomass 5 Almond & Mean & $3,273.7$ & $1,757.8$ & $1,788.5$ & $2,924.8$ \\
tree prunings (tn/yr) & St. dev & $3,969.3$ & $2,734.5$ & $2,680.1$ & $3,522.7$ \\
\hline
\end{tabular}

It can be seen that the results lead to similar findings for all stochastic parameters. In all cases, MSW is the primary fuel to be used. Care should be taken when interpreting the results though: in the case of biomass types that are used in small quantities (such as wheat straw, cotton stalks and olive tree prunings) the standard deviation is very high compared to the mean value. This is a consequence of fitting a distribution to the results as well as of the fact that changing the location of the unit changes the local availability of each biomass type. In reality, these variables do not take negative values, and the high standard deviation denotes the significant number of zero values together with several small values of these variables within the stochastic analysis. 